\title{
The Social Dimension of Asynchronous Learning Networks
}

\author{
Rupert Wegerif \\ Centre for Language and Communication \\ School of Education \\ The Open University \\ Walton Hall, Milton Keynes, MK7 6AA \\ tel: $+44(0) 1908653680$ \\ fax: + 44 (0) 1908654111 \\ e-mail: R.B.Wegerif@open.ac.uk
}

\begin{abstract}
This paper argues that the social dimension is important to effectiveness of Asynchronous Learning Networks (ALNs) and needs to be taken into account in the design of courses. Evidence from an ethnographic study of the Teaching and Learning Online (TLO) course offered by the Institute of Education Technology at the Open University is presented in support of this argument. This study found that individual success or failure on the course depended upon the extent to which students were able to cross a threshold from feeling like outsiders to feeling like insiders. Factors affecting the construction of a sense of community are drawn out from interviews with students. The significance of these findings is discussed in relation to a situated model of learning as induction into a community of practice. Finally recommendations are made for the support of community building in the design of courses.
\end{abstract}

\section{Keywords}

Collaborative learning

Evaluation of ALNs

Situated learning

\section{INTRODUCTION}

Many evaluations of asynchronous learning networks (ALNs) understandably focus upon the educational dimension, either learning outcomes or the educational quality of interactions, overlooking the social dimension which underlies this. In this paper I show, through an ethnographic study of a computer-mediated course, how social factors impacted upon the learning of students. I argue from this evidence that social factors, how participants in an ALN relate to each other, need to be taken into account in the design and development of computer-mediated courses.

When understood as socially situated, learning can be described, following Lave and Wenger [1][2][3] as a process of becoming part of a community of practice. Lave and Wenger's analysis suggests that the key factors in supporting learning are those, which make a community, open to its newcomers, allowing them to participate in its practices and move from peripheral to central status as rapidly and smoothly as possible. Their account of how someone is drawn into full participation depends upon a high degree of interactivity. The examples they draw upon come 
from apprenticeship in face-to-face communities, midwives, tailors, quartermasters and so on ([1], p. 59 - 84). However evidence from studies of computer mediated teaching and learning, many of which stress the support that this medium offers for interactive and collaborative teaching and learning, [4][5][6][7] suggests the relevance of Lave and Wenger's situated learning model to understanding ALNs.

\section{DESCRIPTION OF THE COURSE}

The Teaching and Learning Online (TLO) course offered by the Institute of Education Technology is designed for professional educators who wish to develop courses taught through computer-mediated communication. The course evaluated was the first version of this course run using the FirstClass conferencing system. There were 21 students on this course. Most were based in the United Kingdom with one based in Italy and one in Canada. The students came from a range of backgrounds within the field of education and training. Nine were based in universities, in departments as different as Medicine, Computing and Language, five came from training colleges attached to the police and fire services, four came from colleges of further education, two came from local government and one from a secondary school. Seven of the twenty-one, exactly one third, were women. Eleven members of the course had access only at their office while ten had access from home as well as from work.

The course lasted three months and was taught via the FirstClass conferencing system, which was sent to students on discs before the course began. In addition a print version of the course guide was sent and several course-readers including:

Kaye, A. R. (1992) Collaborative Learning through Computer Conferencing: the Najaden Papers, Heidelberg: Springer-Verlag;

Mason, R. D. (1993) Computer Conferencing: the Last Word, Victoria: Beach Holme;

Rowntree, D. (1981) Developing Courses for Students, London: Paul Chapman.

These course readers were used as background and as a basis for some collaborative exercises in which papers from them were read and discussed. The course was divided into four main stages:

Stage 1: Familiarization

Stage 2: Using Computer-Mediated Communication (CMC) for Teaching and Learning. This stage further divided into three sub-stages each with their own conference area:

The Medium. An open-ended discussion of issues raised by core texts on the nature of $\mathrm{CMC}$ as a medium.

Teaching and learning with CMC. Here the students were divided into two groups depending on their type of institution, one for trainers and one for educators. In their groups they were asked to produce joint responses to five questions on general issues of teaching and learning online: the tutor role, new teaching skills specific to the online environment, how to train tutors, the conditions of effective collaborative learning, and issues of assessment.

Projects. Individual projects for the development of online teaching and learning in students' home institutions.

Stage 3: The Internet World on your Desktop. A course on using the Internet for educational purposes. 
Stage 4: Personal Project Work. This stage included a collaborative learning exercise on Course Design. Students were divided into groups of three and asked to communicate through personal e-mail to work out responses to specific questions about online course design.

As well as the three explicitly collaborative exercises-the Medium, Teaching \& Learning and Course Design conferences-the whole course had a collaborative learning ethos. Unstructured collaborative learning began with students sharing any difficulties that they were having in getting online and continued through all the stages of the course. The course chair, Derek Rowntree, described one of his aspirations for the course as creating a learning community:

In such a learning community, students are liable to learn as much from one another as from course materials or from the interjections of a tutor. What they learn, of course, is not so much product (e.g., information) as process-in particular the creative cognitive process of offering up ideas, having them criticized or expanded on, and getting the chance to reshape them (or abandon them) in the light of peer discussion ([8], p. 207).

The main aim of the course specified in the course guide was that students should, by the end:

produce a coherent argument for or against the use of computer conferencing and Internet resources for training in your own organization and, if appropriate, produce a design for an online course for a specific group of trainees or students, or, for example, a paper outlining the issues involved in implementing online training in your context.

\section{METHOD}

In investigating the course the following sources of information and insight were drawn upon:

- Knowledge of the course and the students stemming from my own participation in the course as an associate tutor.

- Online discussion of collaborative learning and evaluation issues both as an integral part of the course and as a discussion initiated by me in the 'lobby' area around the time of the official end of the course.

- Students' e-mail messages to their tutors.

- Six student responses to an online questionnaire concentrating on the issue of collaborative learning with a small number of open questions.

- Five responses to a similar postal questionnaire.

- Telephone interviews with the six participants who contributed the fewest number of messages to the conference and with four students who were more actively involved in collaborative learning.

- The results of the students' own online evaluation of the course kindly made available to me.

- Taped interviews with the tutors on the course.

The method used to investigate the course relied in part on participant observation and in-depth interviews in order to reconstruct the categories through which the participants themselves interpreted their experience. This describes a broadly ethnographic approach although inevitably, the data was somewhat thinner than would be found in a study of face-to-face interactions and was augmented with the results of questionnaires and what quantitative data on interactions was 
available. McConnell, in his book on the evaluation of ALNs [7], suggests course evaluation take the form of organized discussions between all the participants in a course. This method was tried. Summaries of the students' private discussion on the course proved a valuable source of insight. This study was also influenced by the arguments of Robin Mason [9] in favour of the value of developing interpretative schemas of courses and student experience.

\section{A. Two student voices Judy's view}

Here is an edited version of an e-mail sent by Judy to her tutor at the end of the course. (All names have been changed). In it she draws attention to the role that collaborative learning played in what she clearly feels has been a very valuable experience for her:

I have learned an enormous amount over the past three months and am extremely grateful to the OU team for setting up such an excellent learning environment and I must also add that thanks are due to my peers on this course. Without them I don't think I would have come this far. I'll be posting a note to this effect this evening in the TLO lobby.

I began the course skeptical about the ability to provide genuine interaction using computers, I was proved wrong. I have developed some excellent online friendships over the past three months and have felt very close to all my colleagues on this course.

I began this course wondering if true collaborative learning could take place online, I have been shown it can with the right mix of people. This particular group appears to have worked very well together. We have supported each other and this has greatly aided the learning process. Is this typical of all courses? Have you ever moderated a course where the mix of people was wrong and therefore the interaction not successful? This must have a huge effect on the learning and enjoyment of the course?

I began this course wondering if I had anything to contribute and finish happy in the knowledge that no matter what your background or expertise everybody has something to contribute in conference. At times I had no idea what was being discussed but by expressing my ignorance I hope I helped others who may have felt the same and I also hope I helped those who were in the know to express themselves in layman's terms. This certainly happened to me when I got too involved in my own specialist area. I was asked to explain again, a most useful exercise!!

I began this course wondering how I would fit it in with my other work and family commitments but found the medium provided great motivation and interest. I was always keen to $\log$ in and interested to read the messages. I had to put a lot of time in the early stages but this was to my own advantage and as I have said to you earlier, the more I put in the more I got out. To my great regret I have not been able to contribute as much over the past few weeks and this has been to my distinct disadvantage. I have been logging in regularly and reading the messages posted but I just have not had the time to reflect on my own comments. I realize I am not alone in this but I do get frustrated when I can not put my all in to something!!

I began this course disliking writing and I finish this course a better communicator by text. I have always preferred communicating orally and face to face. This course has shown me it is possible to communicate via text, and that writing can be enjoyable.

Judy was not the only student who felt the collaborative learning on the course had worked well. Of the eleven students in total who responded to the end of course questionnaire seven mentioned collaborating with other students in response to the first question: "What did you like most about the course?" All eleven basically agreed with the statement that CMC was "particularly good at supporting collaborative learning", although one felt that collaborative learning had not been effective for him because circumstances prevented him from logging on often enough. 


\title{
Sujata's view
}

Here, by way of a contrast, are notes taken from an in-depth phone interview with another student, Sujata, who later dropped out of the course. Sujata's own words are combined here with paraphrases from my notes:

\begin{abstract}
The medium is not as asynchronous as it seems. If a bit of time is missed it is hard to catch up. You feel an observer of someone else's conversation. Before making a point you wonder if it has already been made and so have to read back-by the time you are ready the debate has moved on. It is therefore necessary to log on regularly-perhaps every day. This is especially true of collaborative work where your time and the other participants' time have to mesh together.

It is a cold medium. Unlike face to face communication you get no instant feedback. You don't know how people responded to your comments; they just go out into silence. This feels isolating and unnerving. It is not warm and supportive. Perhaps smaller groups would have helped.

Writing does not come easily to me. I don't enjoy it. I find it easier to speak. And reading on screen is difficult ; it is harder to get the real point than for printed text.

This course requires self-discipline. It is too easy to drop out. If you don't log on you lose contact and get no reminders. Perhaps another form of communication is needed as well. We could have benefited from a longer familiarization period. Perhaps the first exercise could have been something not too serious. Perhaps a conference discussing how to conference, when to do it, how to deal with the amount of data.

Special learning skills are needed for conferencing. For example: how to filter the vast amount of contributions. Perhaps these special conferencing skills should be taught.
\end{abstract}

I telephoned Sujata, along with five other students who had not put many messages into the conference area, about one month before the end of the course to ask if she had been having any problems with the course. These low contributors did not return an end-of-course questionnaire so the telephone interviews with them proved valuable to expanding the range of perceptions upon which evaluation and analysis of the course was based. Sujata's first response was to say that she had not contributed more due to pressure of work and limited access. This was the first response of all the six lowest contributors on the course. The views expressed above on the weaknesses of the ALN medium and of the TLO course as supports for collaborative learning only emerged when I questioned her further. The majority of the other low contributors I phoned expressed similar views when questioned sympathetically.

Differences in the level of contribution between students were large. The highest contributor to the available sections of the course sent 122 messages while the lowest sent none. Judy, who praised the course as an environment for collaborative learning, sent 79 messages while Sujata, who was less positive, sent just 4.

\section{B. The threshold experience}

From Sujata's account it looks as if she failed, for various reasons, to cross a threshold into full participation into the collaborative learning on the course. Judy, on the other hand, presents her experience of the course in terms of before and after contrasts implying that a change in state has occurred. This threshold is essentially a social one; it is the line between feeling part of a community and feeling that one is outside that community looking in. For Judy crossing this threshold meant that she switched from disliking her computer to actively seeking out its company in the evenings with a glass of wine. For Sujata not crossing this threshold meant that she saw ALN as a cold and unfriendly medium. The threshold idea recurs in different forms in 
many of the histories and self accounts that students gave. The following selection are real stories but are also chosen to typify aspects of the student experience as a whole.

\section{Judy again}

In her early messages to her tutor Judy said that she sometimes felt like "the novice hiding in the corner". A breakthrough came when she found herself in a group with a specific task which needed organizing-this was in the Teaching and Learning section of stage 2 of the course. Judy waited for someone else to come forward but when no one did she took the plunge and suggested a way for the group to tackle the task. She received a very positive response and found herself at the centre of things. From that time on she felt much more confident about using the medium.

\section{Sarah}

Judy's experience of crossing a threshold was mirrored by others. Sarah contributed very little to the early stages of the conference but was one of the most active by the last stage and expressed regret that it was ending. At first she felt she was watching others from the sidelines. She did not know how to take part. Her barrier, she said, was confidence. Once she had overcome this barrier she felt liberated. Like Judy she described herself as a convert and again, like Judy, she actively advocates the use of ALN in her organization.

Sarah's experience was different from Judy's. Before the TLO course she had little experience of group learning and tended not to like group discussions. She correctly surmised that the most active contributors on the course seemed to have had previous experience of group facilitation and group learning. For her, enjoying collaborative learning was a new experience. She wrote on her online questionnaire response:

It's an awful admission but I think I like, and am better at, communicating using text and a computer than I am at face to face communication in certain circumstances.

Gender was, she felt, an important factor in this. She worked in a male dominated environment where she found it difficult to express herself adequately at meetings. In meetings colleagues often competed in taking the floor and point scoring rather that cooperating. She felt that because in CMC there is not the same competition over turn taking or the same need to think on your feet it can provide a more congenial medium for collaboration. She also found that it allowed her to get some distance on the whole process of communication and to understand how it works. In fact she said, in a follow-up telephone interview, that:

Having done the online course I am better in a group. I have more of a feel for it - of allowing others time to speak ... It has helped me in going into groups.

\section{Daniel}

Daniel had considerable experience of group learning before the TLO course and did not lack confidence but none the less felt that he had failed to cross the threshold into effective collaboration. He only had access from work and via a long-distance phone line, the cost of which meant he was very cautious about taking up time online. He felt that there was an in group of people with almost unlimited access and that he could not be part of it for technical and practical reasons.

Although he felt that collaborative learning had not, in his phrase, "taken off" for him, he none the less told me he had learnt more on this course than on any of the other numerous courses that he had taken. Like both Judy and Sarah he was very enthusiastic about the impact of the course 
on his life and way of working. This impact came more from seeing the potential rather than from actually realizing that potential for himself.

Daniel was not alone in feeling that technical problems and lack of time had condemned him against his wishes to feeling like an outsider. At least two other students told similar stories.

Daniel's view that an in group had formed was supported by interviews with students who were perhaps part of this group. They described the warm friendly atmosphere in the café conference area (a students-only area barred to me) but noted that roughly the same group of about seven students usually seemed to interact there. This in-group of students all had access to the conferencing system of the course both at home and in the office.

\section{Discourse conflicts}

The threshold phenomena between insider and outsider status appeared to be related, in a complex way which I am as yet unable to fully explicate, with another kind of barrier, or barriers, related to the perception of differences in the language and style of contributions. Like Sujata, many students noted feelings of nervousness in posting messages. They were anxious about how their use of language would be received by the other students.

\section{Written versus spoken mode}

The course guide quoted a former student, Harry MacMahon, referring to the written medium of online conferencing as say-writing-a cross between writing and speech. This reflected the thesis work of Simeon Yates [10] which argued that CMC encourages and supports a new type of genre or mode which combines features of written mode with features of spoken mode. Yates applied a framework taken from the linguist Halliday who characterized the difference between written and spoken modes, modes which can be found in both speech and writing, in terms of textual features such as lexical density, clause structure, and nominalization whereby processes are turned into nouns making written texts denser in meaning. A good introduction to Halliday's account of the differences between modes is provided by Eggins ([11], p.56-66).

The line taken by the course guide and the tutors was clear in supporting a casual and spoken style using the written medium of electronic conference messages. One tutor on the course told me that he always put deliberate spelling mistakes in his early messages to help the students relax. On Lave's model we could say that, as an old-timer in the community, he was modeling the behaviour he wanted the students to adopt. However not all the students felt equally comfortable with this relaxed style. Considerable concern and anxiety about the form of messages was evident in an early debate in the lobby of the conference about spelling mistakes and the need for spellcheckers. Several students continued to produce carefully prepared pieces in written as opposed to spoken mode throughout the course. It seemed that the dimension of written to spoken mode was one of social tension in which, interestingly, the spoken mode had the higher status because associated with the tutors and with fluency in the use of the medium.

These remarks are speculative. They suggest the need for follow-up studies of collaborative ALNs using detailed discourse analysis to explore changes in the mode of contributions of students over time and how this relates to their self-perceptions. Such a detailed linguistic study of contributions to an ALN over time is planned for the future using computer-based text analysis software (see [12] for an account of the methodology). It is hoped that such studies will provide more objective linguistic evidence, to combine with and support, or challenge, insights gained through self-reports and participant observation. 


\section{Tom and the education/training divide}

Tom's account illustrates another conflict of discourses which, although related to the conflict between spoken and written modes, was more content focused. Tom contributed early on but then fell away from the course. The main reason he gave for this was pressure of work, but he also acknowledged his feeling of being daunted by the quality and quantity of the contributions of others. He felt that they knew much more than he did about the subject area and that he had little of value to say. He reported thinking:

I can't contribute at a high enough level so let them get on with it.

A number of others mentioned very similar reactions. Indeed one student raised this in an early conference and sparked a lively debate on the issue.

Another student who, like Tom, made few contributions to the course and, like Tom, spoke of not knowing as much about educational matters as some of the others, showed a hint of irritation in his postal questionnaire response writing that he soon lost interest in messages which were too deep for him. He claimed that the variety of backgrounds students had was too great to support effective collaboration. This student - a training officer with the police - thought that the division of students into two groups, one for those with a training background and another for education which took place for the Teaching and Learning section of stage 2 of the course, was an excellent idea but came too late. The same student also suggested that the problem was differential knowledge and that there should be more preparatory work to bring them all up to the same level.

\section{The social impact of the medium}

Some have argued that ALN is a more effective support for collaborative learning than other teaching mediums [4][7][13]. The majority of students agreed with this view. So far I have focused on the social experience of communication online. In this section I will look at indications that the nature of the medium influenced the social interactions it carried.

\section{An ideal speech situation?}

Sarah's account of her experience given above strongly supports the view that CMC can be a better support for collaborative learning than face to face discussion. She found that the gender bias she experienced in meetings in her place of work was not present in CMC and so she was able, after a period of watching, waiting and learning from others, to engage more effectively in discussion than she ever had before. In Lave and Wenger's terms she moved from "legitimate peripheral participation" to centrality in the practice of collaborative learning (as described above by Derek Rowntree) and the medium of CMC helped her to do this in a way that face-to-face meeting had not done.

It might be thought that the reason for this was simply the different nature of the community she encountered online from her community at work. Against that interpretation she specifically pointed out that her difficulties with face-to-face meetings came from not being able to think quickly enough when put on the spot or to demand her fair share of the talk. With CMC on the other hand, she could take as much time as she liked before responding and no one could prevent her from taking a turn whenever she wanted to.

These differences between CMC communication and face-to-face communication have been pointed out by David Graddol [14] and are reiterated by David McConnell [7]. The conclusion 
from both these writers appears to be that CMC supports an egalitarian style of communication in which everyone can participate more easily. This might suggest that CMC might be a better medium for establishing what Habermas [15] calls an ideal speech situation: that situation which, through the elimination of all forms of coercion and through ground rules allowing all to speak, best supports the force of good arguments winning out over other, less rational, factors. Habermas's socially situated account of rationality, communicative rationality [16], has been linked to accounts of the ground rules that best support collaborative learning in educational contexts [17]. It would be very interesting if it could be shown that ALNs support the sort of free and open encounters between ideas, which is the basis of communicative rationality, more effectively than other media.

The equality of access to debate which Habermas's ideal speech situation depends upon was clearly not always felt to be operating on the TLO course. A number of students expressed considerable frustration at the inequality of access which stemmed from their different situations. One student spoke of an in group of academics with unlimited access and technical support provided by their institutions who were able to come online at any time of day or night and stay online for long periods and so dominate the discussion.

Also speaking against the suggestion that CMC can support an ideal speech situation one student claimed that in many ways the CMC format, combined with a tendency several of the participants had of sending quite long and carefully prepared messages, made critical interaction more difficult. He claimed that, in face-to-face discussion, people often anticipated interruptions and rebuttals, and could indicate that they were receptive to possible criticisms of what they said. However where someone had expressed something in a long and carefully prepared message sent to the conference he felt it would seem rude to criticize it without commenting on it fully, and because that would often take too long he tended to let it pass in a way he would not have done in a face to face context. He suggested that all participants be strongly encouraged to keep messages short and informal.

This student claimed that the style of the interaction on the course did not include much argumentation. On the whole people learnt from each other through the accumulation of different perspectives more than through critically challenging and working out arguments together. I noticed only a few cases were a statement by one student was explicitly criticized by another student leading to it being amended and justified with arguments. There were many more cases however, where this kind of critical process was perhaps implicit in the way some themes were taken up and others ignored.

It is not clear to what extent, if any, the reported bias on the course towards a cumulative rather than an argumentative style was an effect of the CMC medium. Another student, questioned on this topic, suggested that the cumulative style of knowledge construction which predominated was a function of the tasks set and the short experience the participants had of working together.

\section{Metalinguistic comments}

David Graddol writes that CoSy, a CMC system, could support metalinguistic comments without diverting the flow of conversation [14]. This was also evident on several occasions in the TLO course using FirstClass. For example in the education sub-conference of the Teaching and Learning exercise during stage 2 of the course there was the following message:

Wednesday, November 23, 1994 9:01:06 p.m.

Educat'n Item 
From: M.....

Subject: Why is this different?

To: Educat'n

This conference feels different from the others to me. Is it like that for the rest of you, and do you have any ideas why it should be so?

My own guesses are to do with two factors, that we're a smaller group and we've something fairly well-defined to concentrate on. I quite miss the rest of the gang when I'm here, but feel it's getting somewhere faster.

m.....

Several other messages followed and then a response to this message

Wednesday, November 23, 1994 10:06:00 p.m.

Educat'n Item

From: D.....

Subject: Re: Why is this different?

To: Educat'n

Yes it does feel different. I feel as if we are more in control in this conference. We are having to make more of the decisions (i.e., how to organize ourselves). I'm not sure which I prefer though. At times I like being autonomous at other times I want the tutor to step in and give me a push in the right direction!!!

This sort of explicit self-reflective statement is of undoubted value to learning but not easy to achieve in face to face conferencing where there is more pressure to keep to a single thread.

\section{Reflection and asynchronicity}

Some have claimed that the asynchronicity of ALNs, which means that there is no pressure for an immediate response, allows for more reflection. This claim too received support from the students on TLO. Several questionnaire responses referred to how the written-down contributions provided an objective record which made reflection easier. The following quote from a phone interview with a student goes into more detail:

Whereas in a face to face conference if someone raised an issue that was not really important to what you were doing you'd say look we can't discuss that - we've booked the room for two hours we have to get on. In CMC it might niggle and you go away and think about it and maybe get a book down from the shelf and come back the next day with some ideas on it ...

One implication of this student's claim is that CMC discussion can sometimes combine different types of thought. As well as the quick response of the conscious surface of the mind there is the possibility of the slower and often more creative process in which thoughts nag away at the back of your mind and new connections are forged.

However asynchronicity was not always found to be helpful. Sujata has already been quoted pointing out that CMC is not as asynchronous as it seems. She was not alone in complaining that, when any time was missed, the messages build up and become a daunting prospect to read through. Five of the students who contributed the least number of messages mentioned this as an inhibiting factor. It was a particularly significant factor for those who came onto the course late and then found it difficult to catch up into a sense of being part of a dynamic conversation.

\section{Features of the conferencing system}

Judy, who had felt herself a computer novice before starting the course, felt that the appealing nature of the FirstClass conferencing system was the most important factor in supporting 
successful collaboration online. She claimed it provided a sense of a shared space in which people could work together. All the students praised First Class for its ease of use and its pleasant feel.

\section{The TLO 'lobby'}

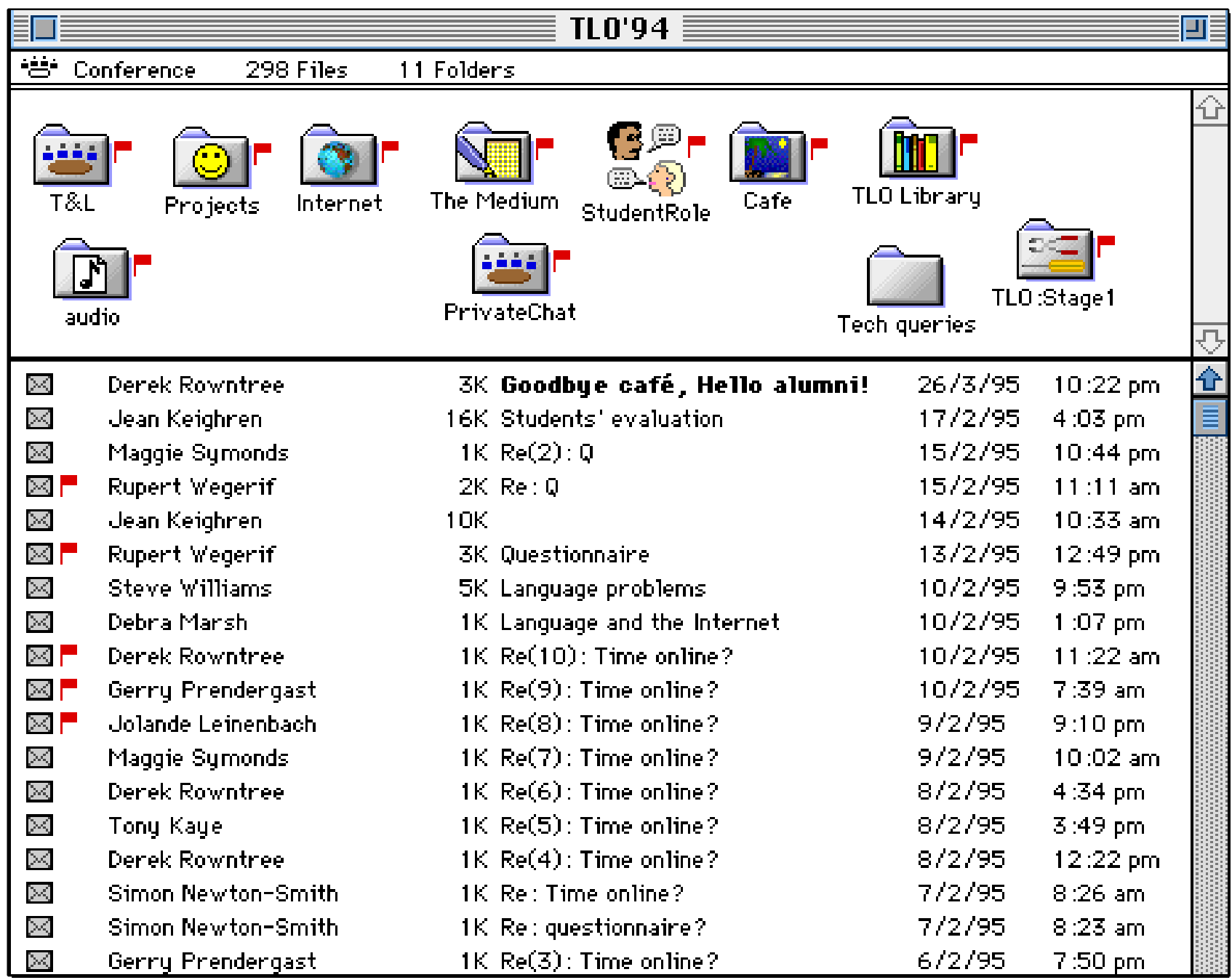

FirstClass provides a spatial metaphor rather like a house in which shared messages are in the lobby and then different rooms open up into the different sub-conferences. This metaphor seemed to provide a positive and welcoming image for those starting to use the system. Here is one message from a brief discussion on the idea of a lobby which developed spontaneously in the TLO lobby area early on in the course. It is a reply to message describing the role of lobbies in Glasgow tenements as a home for dossers and is included in full to give an example of what might be called the community forming style of some messages:

Sunday, November 6, 1994 9:37:43 am

From: E....

Subject: Re: Jeremy's lobby and Lobby Dosser

To: TLO 94

>> So much for the cultural history of Glasgow -- for the time being. $\ll<$ 
That's it P..., raise the cultural milieu of this course! I have to admit that since I signed up I've been feeling like a chanty rassler (etymology... well, no, maybe not) at a musical soiree. Now I feel at home.

In terms of rooms, though, the lobby reminds me of the foyer of a cinema; the place where you stock up on hot dogs, popcorn, and conversation before going in for the big picture. A pleasant place to be, and to come back to.

E....

One strength of FirstClass as a support for the social process of learning was illustrated when a topic-the student role-that had taken over the discussion in the lobby area was transferred to its own specially created room. This seemed a natural process, as if a huddle of people had forming in a lobby area and then gone off to continue their spontaneous debate in a meeting room. In its own space the debate on the student role continued strongly undiluted by the more general messages appropriate to the lobby area.

It was interesting that none of the students mentioned the limitations of FirstClass in supporting threading (the linking of messages under topics and sub-topics as they develop over time) often noted by those more expert in conferencing systems. FirstClass is not as technically proficient in showing the different branches and levels of debate in a topic as some other systems. For example if the first message was titled "Collaborative Learning" the next in reply to this would be given the title "Re: Collaborative Learning" and the next " $\operatorname{Re}(2)$ : Collaborative Learning" and so on. If, at a later date, I returned to "Re: Collaborative Learning" to take up a theme in it which had not been taken up in the discussion, my reply would be titled only "Re(2): Collaborative Learning" duplicating an existing title and giving no indication of the branch in the debate that had occurred. This is clearly a technical limitation which could be remedied. However most students did not find this a problem as they opened up all the messages and got a feeling for what was happening in the debate based more on the content of messages than on their titles.

\section{COURSE STRUCTURE}

Despite the desire of the course tutors to encourage free and open discussion it appeared from the questionnaire returns and other feedback as if students preferred the more structured exercises. Of the nine students who answered the question "In which parts of the course did you feel you benefited most from working with others?" six said the Course Design exercise which took place in stage 3 of the course towards the end. In this part of the course students were split into groups of three and asked to communicate with each other by personal e-mail in order to prepare a report on a particular aspect of course design and implementation, for example, the role of online tutors, course economics, evaluation.

One student was possibly expressing a common feeling when she wrote on her online form:

I think I failed to benefit in stage 2 because of lack of understanding of how to go about group work - I think that more direction from moderators tutors would have helped here. Although I think I learned from my mistakes, it's not really a very rewarding experience. I think I benefited from the final stage because of the learning gained from the first experience and because that section of the course was more clearly managed by the moderator.

Telephone interviews with those who participated the least showed that a number of them had been unhappy with what they perceived as the relative lack of structure early in the course. Lack 
of focus and a tendency for the debate to branch off in too many different directions were mentioned.

If most people appreciated the more structured small group exercise at the end of the course it was partly because some at least had learned how to collaborate more effectively through taking part in the rest of the course. It may be that those students who found the more open-ended exercises difficult to engage in early on in the course would have appreciated them more at a later stage.

\section{RECOMMENDATIONS}

From this analysis of the social dimension of one course, and how this impacted upon the experience of learning, it is possible to draw certain conclusions and to offer recommendations for course design that takes the social dimension into account.

\section{A. Overcoming differential access}

For the purpose of forming a community and for the purpose of effective collaboration it is important that students have as equal as possible access to the shared conversation. Having access only at work during office hours was one key reason for some students contributing little and feeling left out of the course. Perhaps it could be stressed more that to benefit from the course students should have access from home.

Students who came online later than others faced an already established community which they found it more difficult to join and an ongoing learning experience which they found it difficult to catch up with. It would be better if all could start together.

\section{B. Overcoming conflicts of discourses}

Another significant cause for feeling alienated from the course was the feeling of some that the course was dominated by a group that spoke a different language from them. The students on the course, although all involved in education or training, came from different backgrounds. This may always be a problem, however it is possible that with a sufficiently strong sense of community students with less experience of collaborative learning environments would be able to overcome fears of revealing ignorance.

This experience of difference was made worse by having the most abstract and unstructured exercises first in the course. The difficult exploratory approach this called for inevitably showed up differences in students' learning styles, backgrounds and confidence levels.

The first priority should therefore be to build a sense of community through carefully structured exercises in which differences between students are not so obviously significant. Many students suggested, for example, that they would have benefited from a warm-up period with light-hearted exercises which were aimed more at getting to know each other than at formal learning.

\section{Staging exercises to move from more structured to more open}

On the course evaluated, the collaborative exercises moved from the least structured and most open style of exercise with the whole intake at the beginning through an intermediate exercise with clearer questions and groups of 10 or 11 to the final exercise which was the most structured and involved groups of three. Most students expressed a preference for this last stage of the 
course which made them feel more secure and more supported. On the other hand, if the aim is to liberate students in the medium of collaborative learning, then open and less structured exercises are required at some point.

Situated models of teaching and learning generally accept the educational principle of "scaffolding" [18] whereby learners are introduced gradually to complex new skills through the activity of teachers who coach simplified versions initially and then increase the degrees of freedom (remove the scaffolding) towards a point where the teacher is no longer needed. This principle applied to the coaching of the complex skill of collaborative learning online would suggest that it is sensible to provide maximum structure and support at the beginning of the course and gradually take this away to move towards greater freedom and student-centered learning by the end of the course.

\section{Providing teaching opportunities}

One student on the TLO course suggested that there should be more opportunities to lead group learning experiences. Crossing the threshold from newcomer status to that of old-timer status requires that, to some extent, students to take control of the online learning experience and structure it for themselves. Providing opportunities for this to happen, after a community has been given a chance to form, is clearly important.

\section{E. Allowing time for reflection at the end}

The process of taking charge of the process of learning is aided by reflection on the process itself. In the context of an ALN course this could be supported by dedicating a specific period of time to it, for example a period at the end of a course, perhaps the last week, for a facilitated discussion of what had been learned and how it had been learned. This discussion time could also provide valuable feedback on the effectiveness of different aspects of the course.

\section{F. Discussion}

Looking at aspects of the medium and of the course structure in terms of their impact on collaborative learning confirms the importance of the social dimension. One illustration of this is that the technical weaknesses of FirstClass in supporting threading were not noticed as a hindrance by students; instead it was universally praised for its feel. It provided an environment for social interaction in which people could feel at home. Another illustration is that problems of different access to the course were experienced most strongly through their impact on social relationships. Some of those with limited access felt like outsiders and this reduced their motivation while some of those with greater access formed a highly collaborative friendship group chatting together about many issues other than the course. This does not mean that factors which are not normally seen as social, such as software design or the limits on access, were unimportant but that their effect on the success of the course was mediated by their effect on the social process of forming and supporting a collaborative learning community.

Lave and Wenger's model of teaching and learning, referred to in the introduction, which describes learning as the process of becoming part of a community of practice, can illuminate the relationship between the social dimension and learning on the TLO course. Applying this model the TLO course can be seen as a learning community, designed to induct students into a particular practice. The tutors and associate tutors on the course acted as a seeding of old-timers modeling good online communication styles and drawing the newcomers in to form a community with them. The main aim of the course was to turn these newcomers into old-timers capable of setting up and running an online course of their own to draw further newcomers into the shared practice 
of online teaching and learning. While collaborative learning was emphasized as the main pedagogic method of the course the course itself was designed in a way that focused upon imparting the skills and knowledge necessary to run further online courses. The success of this aim of the course was assessed through the quality of the final reports each student produced which was an account of a project for developing an ALN in their context. While these final reports were not given a grade they were discussed by all on the course, given detailed feed-back and, where they were felt by the tutors to come up to standard, a diploma was issued. Learning how to engage effectively in collaborative learning online was not focused upon explicitly in the same way. It occurred instead as a by-product of the main educational aim. This is where applying Lave and Wenger's model is useful. It draws attention to the social dynamic that underlies learning, particularly the mechanisms through which students succeed, or fail to succeed, in moving from being legitimate peripheral participants to becoming more central members of a community.

Forming a sense of community, where people feel they will be treated sympathetically by their fellows, seems to be a necessary first step for collaborative learning. Without a feeling of community people are on their own, likely to be anxious, defensive and unwilling to take the risks involved in learning. Research in the field of collaborative learning in education (summarized in [17] ) also suggests that it is best supported by a particular style of communicating that relates to Habermas' model of communicative rationality. This style is democratic, respectful, open to challenges, prepared to give grounds for statements and seeking critically grounded consensus. The experience of students on the TLO course lends some support to the idea put forward by McConnell and others that CMC is a naturally effective support for this collaborative learning mode or style of interaction. As one student wrote on his online questionnaire form:

The benefits of collaborative learning were derived from taking part in a developing conversation where many of the replies were much more considered than might have been the case had the same people met and talked together over several hours. Questions were raised, answered, developed, returned to and reconsidered in a much more polite and considerate manner than would have been the case in the face-to-face situation.

\section{CONCLUSION}

I began this paper with some student responses which showed first how central collaborative learning was to feelings of success or failure on the course and second how important social factors were to this collaborative learning. Those who felt that they had gained most from the course moved from feeling like outsiders to feeling like insiders. Those who fell away or felt that they had failed to learn as much as they might were those who felt that they had remained outsiders unable to cross the threshold to insider status. The findings of the study point to several factors which can influence the movement of students from being outsiders to becoming insiders, including features of the course design, the role of moderators, the interaction styles of course participants and features of the technological medium used. As well as its more specific conclusions and recommendations, this study has illustrated a method for researching the social dimension of ALNs and put forward the beginnings of a conceptual framework, including the concept of the difficult threshold between insider and outsider status, which may prove of general value in understanding the impact of the social dimension on learning on ALNs and how this impact can be taken into account in course design. 


\section{ACKNOWLEDGEMENTS}

This report is based on an evaluation funded by the Delta programme of European Community Commission as part of the European Open University Network project.

I am grateful to all the students and the tutors on the TLO3 course who generously lent me their voices.

I would like to thank Robin Mason, Tony Kaye and Derek Rowntree, in particular for their support and encouragement of the research on which this paper is based.

\section{REFERENCES}

1. Lave, J. and E. Wenger, Situated Learning: legitimate peripheral participation. Cambridge: Cambridge University Press(1991).

2. Lave, J., Word problems: a microcosm of theories of learning, in Context and Cognition: ways of learning and knowing, P. Light and G. Butterworth, Editors. Harvester-Wheatsheaf.: Hemel Hempstead. (1992).

3. Lave, J., Situated Learning in Communities of Practice, in Perspectives on Socially Shared Cognition, L. In Resnick, J. Levine, and S. Teasley, Editors. American Psychological Association: Washington, D.C. (1991).

4. Harasim, L., et al., Learning Networks. Cambridge, Ma: MIT (1995).

5. Mason, R. and A. Kaye, eds. Mindweave: Computers, Communication and Distance Education. . Pergamon: Oxford (1989).

6. Mason, R., ed. Computer Conferencing. The Last Word...,. . Beach Holme Publishers Ltd: Victoria, British Columbia (1993).

7. McConnell, D., Implementing Computer Supported Cooperative Learning. London: Kogan Page (1994).

8. Rowntree, D., Tutoring Online. British Journal of Educational Technology, 26, 3 (1995).

9. Mason, R., Evaluating technology-based learning, in Innovative adult learning with innovative technology, B. Collis and G. Davies, Editors. Elsevier: Oxford. (1995).

10. Yates, S., The Textuality of Computer Mediated Communication, . 1993, Unpublished Ph.D. Thesis. Open University.

11. Eggins, S., An Introduction to Systemic Functional Linguistics. London: Pinter (1994).

12. Wegerif, R. and N. Mercer, Using computer-based text analysis to integrate quantitative and qualitative methods in the investigation of collaborative learning. Language and Education, 11, 3 (1997).

13. Harasim, Online Education: a New Domain, in Mindweave: Communication, Computers, and Distance Education, R.D. Mason and A.R. Kaye, Editors. Pergamon: Oxford. (1989).

14. Graddol, D., Some CMC discourse properties and their educational significance, in Mindweave, A. Kaye, Editor. Pergamon: Oxford. (1989).

15. Habermas, J., Moral Consciousness and Communicative Action. Cambridge: Polity Press (1990).

16. Habermas, J., The Theory of Communicative Action. Vol 1. Cambridge: Polity Press (1991).

17. Wegerif, R. and N. Mercer, Computers and reasoning through talk in the classroom. Language and Education, 10, 1 (1996).

18. Mercer, N. and E. Fisher, Scaffolding through talk, in Computers and Talk in the Primary Classroom, R. Wegerif and P. Scrimshaw, Editors. Multilingual Matters: Clevedon, Avon. (1997).

19. Kaye, A., Learning together apart, in Collaborative Learning Through Computer Conferencing, A. Kaye, Editor. Springer-Verlag: Heidelberg. (1991). 